\title{
Restricted TcR $\beta$ chain CDR3 clonotype is associated with resolved acute hepatitis $B$ subjects
}

Dangsheng Xiao ${ }^{1 \dagger}$, Ju Wang ${ }^{2 \dagger}$, Zhitao Chen ${ }^{3}$, Xiuyuan $\mathrm{Jin}^{2}$, Yirui Xie ${ }^{2}$, Dong Yan ${ }^{2^{*}}$ and Jiezuan Yang ${ }^{2^{*}}$ (D)

\begin{abstract}
Background: T cells play an important role in the prognosis of hepatitis B virus (HBV) infection, and are involved in the seroconversion of a patient from HBsAb negative to positive. To compare the T-cell receptor $\beta$-chain variable region (TCRBV) complementarity-determining region 3 (CDR3) in subjects with or without hepatitis $B$ surface antigen ( $\mathrm{HBs} A \mathrm{Ag}$ ) convert to hepatitis B surface antibody (HBsAb), the TcRBV was determined using high throughput sequencing (HTS).

Methods: The clonotype and diversity of CDR3 in peripheral blood mononuclear cells of subjects with resolved acute hepatitis B (AHB, HBsAb+, HBsAg-) $(n=5)$, chronic hepatitis B (CHB, HBsAb-, HBsAg+) $(n=5)$, and healthy controls (HC, HBsAb-, HBsAg-) ( $n=3$ ) were determined and analyzed using HTS (MiSeq).

Results: The overlapping rate of CDR3 clones of any two samples in AHB group was $2.00 \%(1.74 \% \sim 2.30 \%)$, CHB group was $1.77 \%(1.43 \% \sim 2.61 \%)$, and HC group was 1.82\% (1.62\% 2.12\%), and there was no significant difference among the three groups by Kruskal-Wallis $\mathrm{H}$ test. However, among the top 10 cumulative frequencies of clonotypes, only the frequency of clonotype (TCRBV20-1/BD1/BJ1-2) in AHB group was lower than that of HC group $(P<0.001)$. Moreover, exclude the 10 top clonotypes, there are 57 markedly different frequency of clones between AHB and CHB groups (18 clones up, 39 clones down), 179 (180-1) different clones between AHB and HC groups, and 134 different clones between $\mathrm{CHB}$ and HC groups. With regard to BV and BJ genotypes, there was no significant different frequency among the groups. Furthermore, there was no significant difference in the diversity of TCRBV CDR3 among the three groups $(P>0.05)$.
\end{abstract}

Conclusions: Thus, there are 57 TCRBV clonotypes that may be related to HBsAg seroconversion of AHB subjects, but the diversity of TCRBV CDR3 is not significantly related to the HBsAb positive status.

Keywords: T cell receptor, Complementarity-determining region 3, Resolved acute hepatitis B, HBsAg seroconversion, High throughput sequencing

\footnotetext{
* Correspondence: yandonh@163.com; yangyan@zju.edu.cn

${ }^{\dagger}$ Dangsheng Xiao and Ju Wang contributed equally to this work.

${ }^{2}$ State Key Laboratory for Diagnosis and Treatment of Infectious Diseases,

National Clinical Research Center for Infectious Diseases, Collaborative

Innovation Center for Diagnosis and Treatment of Infectious Diseases, the

First Affiliated Hospital, Zhejiang University School of Medicine, Zhejiang

310003, Hangzhou, China

Full list of author information is available at the end of the article
}

(C) The Author(s). 2021 Open Access This article is licensed under a Creative Commons Attribution 4.0 International License, which permits use, sharing, adaptation, distribution and reproduction in any medium or format, as long as you give appropriate credit to the original author(s) and the source, provide a link to the Creative Commons licence, and indicate if changes were made. The images or other third party material in this article are included in the article's Creative Commons licence, unless indicated otherwise in a credit line to the material. If material is not included in the article's Creative Commons licence and your intended use is not permitted by statutory regulation or exceeds the permitted use, you will need to obtain permission directly from the copyright holder. To view a copy of this licence, visit http://creativecommons.org/licenses/by/4.0/ The Creative Commons Public Domain Dedication waiver (http://creativecommons.org/publicdomain/zero/1.0/) applies to the data made available in this article, unless otherwise stated in a credit line to the data. 


\section{Background}

Hepatitis B virus (HBV) can cause acute and chronic HBV infection, liver cirrhosis, and liver cancer, and is a serious threat to human health worldwide [1]. In recent years, with the wide spread of hepatitis $B$ vaccine immunization and the application of antiviral medicine, acute hepatitis B infection has been significantly reduced, and chronic infection has been effectively controlled [2]. The appearance of HBsAb (HBsAg seroconversion) in peripheral blood indicates that the acute hepatitis $B$ subject has recovered with a protective effect on body from recurrent $\mathrm{HBV}$ infection. HBsAg seroconversion (SC) is also an ideal prognosis (favourable outcome) for CHB patients who are undergoing antiviral treatment $[3,4]$.

At present, most of studies on HBsAg SC are based on the virus level of HBV itself, but the exact mechanism of the production of $\mathrm{HBsAb}$ (resulting from HBsAg SC) is still unclear [3]. It is generally believed that host would produce antigen-specific $\mathrm{T}$ cells whose function is determined by the $\mathrm{T}$ cell receptor (TcR) on its surface and these $\mathrm{T}$ cell could help $\mathrm{B}$ cells to produce HBsAb, when a pathogen or a foreign antigen invades a host $[5,6]$. Additionally, the simple description of route HBV transmission is following, hepatocytes are the host cell of $\mathrm{HBV}$. By the interaction between antigens on HBV envelope and the receptors of the hepatocytes, HBV virion is endocytosized and encapsulated as an endosomal vesicle in hepatocytes. More details are shown in our previous report [7]. Moreover, the $\mathrm{HBV}$ antigen is presented to $\mathrm{T}$ cells by MHC I (MHC II) on the membrane of presenting cell, and development of cell-mediated and humoral immunity against HBV (Fig. 1). However, HBV infection would be persistent if the $\mathrm{T}$ cells are not activated effectively and rendered anergy.

$\mathrm{T}$ cell receptor (TcR) is a receptor molecule on the $T$-cell membrane that recognizes the antigen. TcR is a heterodimer composed of $\alpha, \beta$ chains or $\gamma, \delta$ chains, and more than $95 \%$ of mature T-cells in human peripheral blood present the $\alpha$ and $\beta$ chains. TcR is the key element for the $\mathrm{T}$ cell to activate, recognize, and combine with the peptide/MHC complex [8, 9]. The complexity of the TcR structure is mainly determined by the complementary decision region 3 (CDR3) that is encoded by variable $(\mathrm{V})$, diversity (D), and joint (J) and their reorganization and editing. In the process of lymphocyte maturation, different CDR3 genotypes are formed by the rearrangement, insertion, mutation and deletion of V, D, and J. Different genotypes indicate different nucleotide sequences, giving rise to amino acid sequences translated in the ribosome, and forming a variety of CDR3 clones $[10,11]$. Therefore, by measuring the diversity of a specific TcR CDR3 sequence and the frequency change in different physiological or pathological states, we can clearly understand the extent of clonal expansion of corresponding $\mathrm{T}$ lymphocytes, and understand the role of $\mathrm{T}$ cells in HBsAg seroconversion.

In the present study, TcRBV CDR3 clones of resolved acute hepatitis $\mathrm{B}(\mathrm{AHB})(\mathrm{HBs} \mathrm{Ab}+)$ and $\mathrm{CHB}(\mathrm{HBsAb}-)$ were analyzed to explore the different profiles of CDR3 expression in $\mathrm{AHB}$ subjects with $\mathrm{HBsAb}+$ after infection with $\mathrm{HBV}$, to clarify the role of $\mathrm{T}$ cell subsets in the mechanism of HBsAg SC.

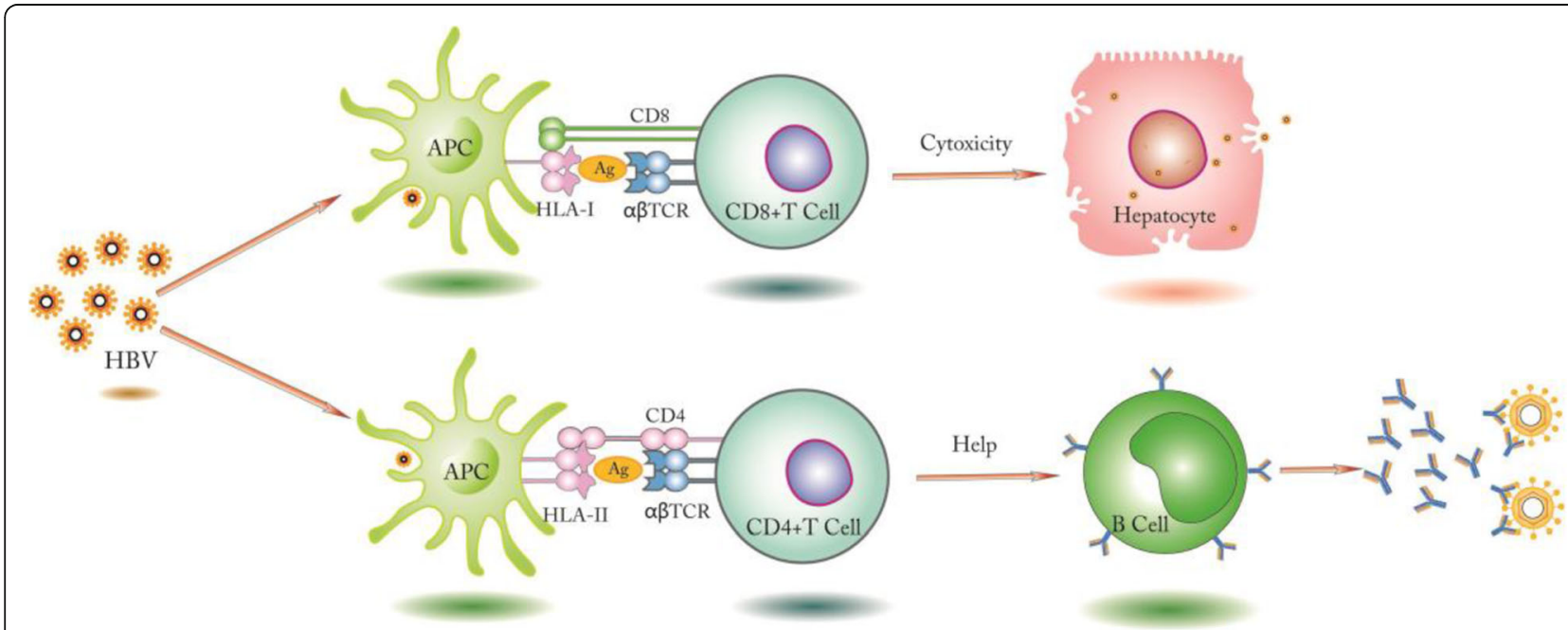

Fig. $1 \mathrm{HBV}$ infection and related immune response. HBV enters hepatocytes or phagocytes, and CD8+/ CD4+ T cells recognize HBV antigens presented by $\mathrm{MHC}$ I or MHC II, then CD8+ T cells are activated and cytotoxic effect on target cells, and the CD4+ T cells help B cells activate and produce antibodies against HBV 


\section{Methods}

\section{Subjects enrolled}

Between January and May 2019, five subjects with resolved acute hepatitis $\mathrm{B}(\mathrm{AHB})$ and five chronic hepatitis $\mathrm{B}(\mathrm{CHB})$ subjects were enrolled in our study. All subjects were selected at the health examination center of the First Affiliated Hospital, Zhejiang University School of Medicine.

Our diagnostic criteria for $\mathrm{AHB}$ and $\mathrm{CHB}$ met the Guidelines for the prevention and treatment of chronic hepatitis B (version 2015) and the diagnostic criteria described in other reports [12]. In brief, the $\mathrm{CHB}$ subjects are defined as those who are with HBsAg-positive (>6 months), HBeAg-positive and HBV DNA detectable, and with abnormal liver function tests. The AHB subjects are collected based on normal biochemical indexes of liver function, and had transient mild symptoms of $\mathrm{HBV}$ infection in the past, at present, HBsAb-positive and HBcAb-positive without any clinical symptoms, absence of HBsAg, and HBV DNA levels below the detection limit, without a history of hepatitis $\mathrm{B}$ vaccination. Additionally, the exclusion criteria for $\mathrm{AHB}$ and $\mathrm{CHB}$ were described in our previous report [10]. Three healthy controls were negative for all HBV serological markers and displayed no clinical or laboratory evidence of other infectious diseases or immunological disorders. Additional characteristics of enrolled subjects at the time of the study are shown in Table 1.

This project and protocols involving human subjects were approved by the ethics committee of the First Affiliated Hospital, Zhejiang University School of Medicine. Informed consent was obtained from each subject enrolled in the study. The study protocol meets the ethical principles of the Declaration of Helsinki (2008).
Biochemical, serological, and HBV DNA load assay

Biochemical indexes of liver function were detected by an automatic biochemical analyzer (HITACHI 7600, Japan) at clinical laboratory of our unit. Plasma samples were used to detect hepatitis $\mathrm{B}$ serological indicators (such as, HBsAg, HBsAb, HBcAb, HBeAg, and HBeAb) with enzyme immunoassays (Abbott, Chicago, IL, USA) according to the test guidance. The HBV DNA level was quantitatively determined using real-time polymerase chain reaction (qPCR) [13] with a commercial kit, and the detection limit is 30 copies $/ \mathrm{ml}$. Briefly, $5 \mu \mathrm{L}$ of serum was added to the reaction mixture containing $38 \mu \mathrm{L}$ of HBV PCR mixture and $2 \mu \mathrm{L}$ of enzyme mixture. Quantification of HBV DNA was performed using a qPCR thermocycler (Applied Biosystem 7300, Foster City, California, USA). HBV genotypes were determined with sequence detection via PCR, the detail was shown in our previous report [14].

\section{PBMC separation and RNA extraction}

Peripheral blood mononuclear cells (PBMCs) were isolated from peripheral venous whole blood samples using Ficoll (Haoyang, Tianjin, China) density gradient centrifugation. Immediately, total RNA was extracted from PBMCs using Trizol (Invitrogen, Carlsbad, CA, USA) following the operating instructions, the more detail following our previously report [10]. Finally, the quality of RNA was evaluated using an Agilent 2100 Bioanalyzer (Agilent Technologies, USA).

Construction of sequencing library and TCRBV sequencing The full-length TcRBV gene was amplified by 5' RACE unbiased amplification protocol, and constructed the sequencing libraries. Concentration of the TcRBV library, integrity of the fragment, size of the inserted fragment,

Table 1 Demographic and clinical characteristics of the enrolled subjects

\begin{tabular}{|c|c|c|c|}
\hline Characteristics & AHB & $\mathrm{CHB}$ & $\mathrm{HC}$ \\
\hline No. subject & 5 & 5 & 3 \\
\hline Gender (male/female) & $5 / 0$ & $4 / 1$ & $1 / 2$ \\
\hline Mean age (years) & $32.3 \pm 7.9$ & $43.3 \pm 12.3$ & $34.3 \pm 9.9$ \\
\hline ALT level (U/L) & $14.0(10.0-30.0)$ & $94.5 \pm 37.7$ & $23 \pm 8.2$ \\
\hline TBi (umol/L) & $11.0 \pm 5.3$ & $13.0(9.5-13.4)$ & $7.9(6.4-16.5)$ \\
\hline HBV DNA (log10, Copies/mL) & UD & $7.5 \pm 1.5$ & UD \\
\hline HBV genotype & UD & $2 B / 3 C$ & UD \\
\hline HBeAg (PEIU/mL) & $0.38(0.07-0.40)$ & $218.67(0.30-459.54)$ & $0.25 \pm 0.16$ \\
\hline $\mathrm{HBCAb}(\mathrm{S} / \mathrm{CO})$ & $3.13(2.09-5.73)$ & $8.77 \pm 0.68$ & $0.10 \pm 0.02$ \\
\hline HBsAg $(\log 10 \mathrm{IU} / \mathrm{mL})$ & UD & $4.0 \pm 0.8$ & UD \\
\hline $\mathrm{HBsAb}(\mathrm{mlU} / \mathrm{mL})$ & $626.9(358.1-670.9)$ & $0.4(0.2-0.9)$ & $0.0(0.0-0.135)$ \\
\hline
\end{tabular}

All subjects are of Chinese Han ethnicity. Values are expressed as median (Q1-Q3), normal distribution data expressed as mean \pm SD (standard deviation), unless otherwise indicated

UD undetectable

Normal values: $\mathrm{ALT} \leq 40 \mathrm{U} / \mathrm{L} ; \mathrm{TBi} \leq 21 \mathrm{umol} / \mathrm{L}$ 
and effective concentration of the library were detected and quantified using Qubit 2.0 Fluorometer, Agilent 2100 and Q-PCR respectively. Subsequently, the TcRBV library was sequenced using the ImmuHub ${ }^{\text {tw }} T C R$ profiling system at the deep level (ImmuQuad Biotech, Hangzhou, China). The raw sequence was screened, the low-quality sequences with splices were removed, the sequencing background was filtered [15], and the sequence obtained was compared with the reference sequences of the international ImMunoGeneTics (IMGT) database (www.imgt.org). The nucleotide and amino acid (AA) sequences of TcR $\beta$ chain complementarity determining region 3 (CDR3) were determined, and those with outof-frame and stop codon sequences were removed from the identified TcR $\beta$ chain repertoire as per more detailed steps described in the previous report $[16,17]$.

\section{CDR3 diversity analysis}

The diversity of CDR3 sequence was analyzed and presented using Pielous / diversity, Shannon entropy index (SE), and Inverse Simpson's index (IS), which have been widely used for assessing the richness and diversity of TcR data [18-20]. The formula is as follows:

$$
\mathrm{SE}=-\sum_{i=1}^{s} P i \ln P i
$$

$P \mathrm{i}$ is the proportion of characters belonging to the $\mathrm{i}^{\text {th }}$ clone type of $\mathrm{i}$ in the string, $\mathrm{S}$ is the total number of TcRBV.

$$
\text { IS }=1 / \sum_{i=1}^{s} P i^{2}
$$

$P \mathrm{i}$ is the proportion of characters belonging to the $\mathrm{i}^{\text {th }}$ clone type of $\mathrm{i}$ in the string, $\mathrm{S}$ is the total number of TcRBV. To determine the usage of each $V / D / J$ gene in the TcRBV repertoire, the number of each $\mathrm{V} / \mathrm{D} / \mathrm{J}$ gene assigned to different TcRBV clonotype was summed.

Baroni-Urbani and Buser (BUB) overlap index [21] was calculated according to respective formulae, and the more detailed method was described previously [16].

\section{Statistical analysis}

The statistical programming language $\mathrm{R}$ (version 2.8.1) and GraphPad Prism 7.0 Package (San Diego, CA, USA) were used to analyze the experimental results. The mean \pm standard deviation (SD) was used to describe the data of the normal distribution, and the data for the skewed distribution was described by the median ( 25 quantiles, 75 quantiles). The Kruskal-Wallis $\mathrm{H}$ test was used for comparing the SE and IS ratio, clonal overlapping rate, and the frequency of dominant genotypes among the three groups. Mann-Whitney U test was used to compare two groups among the three groups. The frequencies of the clone and $\mathrm{V}$, J genotypes were compared by independent sample T-tests. Comparisons between groups were performed using two-tailed Ttests. $P$ values $<0.05$ were considered statistically significant.

\section{Results \\ TcRBV CDR3 sequence immune repertoire (IR)}

The original sequences obtained by high-throughput sequencing (HTS) were converted to raw reads by filtering the low-quality sequences such as by removing the sequence with length less than $150 \mathrm{bp}$, the spliced sequences, and cutting out the continuous low-quality bases with a mass value less than 19 at both ends of the sequence. The sequence with undetermined base proportion more than $10 \%$ was also removed, so that more than $80 \%$ of the filtered sequence had a sequencing quality value (Pherd value) of more than 30 . Additionally, V, $\mathrm{J}$, and CDR3 regions of TcRBV consensus sequences were identified using BLAST Plus in the IMGT information system using a standard algorithm [22].

\section{Sample amplification and diversity}

There was no difference in the number of reads between the three groups $(P>0.05)$, and in the number of CDR3 or in the unique CDR3 (both, $\mathrm{P}>0.05$ ). However, the ratio of unique CDR3/CDR3 in the CHB group was significantly lower than that in the HC group $(P=0.0348)$, but no significant difference was found between the AHB and $\mathrm{HC}$ groups (Additional file 1: Tab. S1). Additionally, the diversity index was used to represent the diversity of each group, and no significant difference was found among these groups.

\section{Frequency of $\mathrm{V} / \mathrm{D} / \mathrm{J}$ combination compared between groups}

All $V / D / J$ combinations of each sample were obtained by IMGT database comparisons, and the top $10 \mathrm{~V} / \mathrm{D} / \mathrm{J}$

Table 2 Top ten cumulative frequencies of V/D/J gene combinations

\begin{tabular}{ll}
\hline V/D/J & Frequency \\
\hline TRBV24-1/TRBD2/TRBJ2-1 & 0.468146 \\
TRBV5-1/TRBD1/TRBJ1-2 & 0.142069 \\
TRBV20-1/TRBD1/TRBJ1-2 ${ }^{\mathrm{a}}$ & 0.130259 \\
TRBV9/TRBD1/TRBJ1-1 $^{-1}$ & 0.103324 \\
TRBV25-1/TRBD1/TRBJ2-5 & 0.092293 \\
TRBV7-8/TRBD2/TRBJ2-7 & 0.072890 \\
TRBV4-2/ /TRBJ2-1 & 0.058674 \\
TRBV14/TRBD1/TRBJ1-1 & 0.050959 \\
TRBV7-6/TRBD2/TRBJ2-1 & 0.049602 \\
TRBV12-4/TRBD1/TRBJ2-4 & 0.043804 \\
\hline
\end{tabular}

a There is significantly difference between AHB and HC groups 
gene combinations with the highest frequency from 13 samples were selected (Table 2). There was no significant difference in the frequency of the top $10 \mathrm{~V} / \mathrm{D} / \mathrm{J}$ gene combinations among the three groups, except the $\mathrm{V} / \mathrm{D} / \mathrm{J}$ (TcRBV20-1/BD1/BJ1-2) between AHB and HC group (average frequency, 6.457E-6 vs. 8.310E-6, $P=6.434 \mathrm{E}-3$ ).

Furthermore, the remaining (excluding the top ten) frequencies were compared between the three groups, the clone genotype TcRBV6-4/BD1 (BD2) /BJ2-2 in the AHB group was $1.366 \mathrm{E}-05$ (average frequency), and the frequency of the CHB group was 8.851E-06, the difference between the two groups was statistically significant $(P=0.0021)$. Simultaneously, the clone genotype TcRBV6-4/BD1 (BD2) /BJ2-2 in the HC group was $1.068 \mathrm{E}-05$, the difference between the $\mathrm{AHB}$ and $\mathrm{HC}$ groups was also statistically significant $(P=0.0407)$. Furthermore, there were 57 different clones between the
AHB and CHB groups, 180 different clones between the AHB and HC groups, and 135 different clones between the $\mathrm{CHB}$ and $\mathrm{HC}$ groups with significant difference (Tables 3, 4 and 5; Additional file 2: Fig. S1, S2).

\section{Frequency of TcRBV (BJ) compared between groups}

We identified $48 \mathrm{BV}$ and $13 \mathrm{BJ}$ segments, of which 48 BV segments were merged into 27 segments. These results were used to analyze the BV and BJ segment usage (percentage) in each sample, and no significant difference was found for each sample (both, $P>0.05$ ) (Fig. 2) except BV24 and BJ2-1 of H16 sample. The pie chart was used to indicate the richness (frequency) of each TcRBV family and each TcRBJ (6 BJ1, 7 BJ2) in each group of the three groups, and the frequencies of TcRBV (BJ) between the three groups were compared

Table 3 Comparison of clonal frequency $(V-J)$ between $A H B$ and $\mathrm{CHB}(\mathrm{P}<0.05)$

\begin{tabular}{|c|c|c|c|c|c|}
\hline VJ & $\mathbf{P}$ & Mean value -comparing & VJ & $P$ & Mean value -comparing \\
\hline TRBV27|TRBJ1-4 & 0.00017 & $\mathrm{AHB}<\mathrm{CHB}$ & TRBV6-5|TRBJ1-1 & 0.01937 & $\mathrm{AHB}<\mathrm{CHB}$ \\
\hline TRBV7-2|TRBJ2-3 & 0.00035 & $\mathrm{AHB}<\mathrm{CHB}$ & TRBV4-1|TRBJ1-4 & 0.01939 & $\mathrm{AHB}<\mathrm{CHB}$ \\
\hline TRBV7-2|TRBJ2-2 & 0.00041 & $\mathrm{AHB}<\mathrm{CHB}$ & TRBV7-2|TRBJ2-6 & 0.01990 & $\mathrm{AHB}<\mathrm{CHB}$ \\
\hline TRBV10-3|TRBJ1-4 & 0.00042 & $\mathrm{AHB}<\mathrm{CHB}$ & TRBV7-2|TRBJ1-4 & 0.02215 & $\mathrm{AHB}<\mathrm{CHB}$ \\
\hline TRBV6-2|TRBJ2-4 & 0.00059 & $\mathrm{AHB}<\mathrm{CHB}$ & TRBV5-1|TRBJ1-6 & 0.02320 & $\mathrm{AHB}<\mathrm{CHB}$ \\
\hline TRBV4-2|TRBJ1-2 & 0.00156 & $\mathrm{AHB}<\mathrm{CHB}$ & TRBV5-5|TRBJ1-5 & 0.02323 & $\mathrm{AHB}<\mathrm{CHB}$ \\
\hline TRBV6-4|TRBJ2-2 & 0.00208 & $\mathrm{AHB}>\mathrm{CHB}$ & TRBV28|TRBJ1-3 & 0.02407 & $\mathrm{AHB}>\mathrm{CHB}$ \\
\hline TRBV5-6|TRBJ1-2 & 0.00299 & $\mathrm{AHB}<\mathrm{CHB}$ & TRBV13|TRBJ2-5 & 0.02524 & $\mathrm{AHB}<\mathrm{CHB}$ \\
\hline TRBV4-1|TRBJ2-4 & 0.00319 & $\mathrm{AHB}<\mathrm{CHB}$ & TRBV6-2|TRBJ2-7 & 0.02594 & $\mathrm{AHB}<\mathrm{CHB}$ \\
\hline TRBV5-6|TRBJ1-6 & 0.00432 & $\mathrm{AHB}<\mathrm{CHB}$ & TRBV1 1-3|TRBJ2-1 & 0.02712 & $\mathrm{AHB}>\mathrm{CHB}$ \\
\hline TRBV20-1|TRBJ2-5 & 0.00493 & $\mathrm{AHB}>\mathrm{CHB}$ & TRBV12-3|TRBJ1-6 & 0.02727 & $\mathrm{AHB}<\mathrm{CHB}$ \\
\hline TRBV6-1|TRBJ2-3 & 0.00521 & $\mathrm{AHB}>\mathrm{CHB}$ & TRBV1 1-3|TRBJ1-1 & 0.02987 & $\mathrm{AHB}>\mathrm{CHB}$ \\
\hline TRBV1 1-3|TRBJ2-2 & 0.00598 & $\mathrm{AHB}>\mathrm{CHB}$ & TRBV5-6|TRBJ2-4 & 0.02996 & $\mathrm{AHB}<\mathrm{CHB}$ \\
\hline TRBV14|TRBJ1-6 & 0.00607 & $\mathrm{AHB}>\mathrm{CHB}$ & TRBV5-4|TRBJ2-7 & 0.03061 & $\mathrm{AHB}>\mathrm{CHB}$ \\
\hline TRBV7-7|TRBJ2-5 & 0.00631 & $\mathrm{AHB}<\mathrm{CHB}$ & TRBV6-6|TRBJ1-2 & 0.03276 & $\mathrm{AHB}<\mathrm{CHB}$ \\
\hline TRBV7-2|TRBJ2-4 & 0.00737 & $\mathrm{AHB}<\mathrm{CHB}$ & TRBV29-1|TRBJ2-7 & 0.03291 & $\mathrm{AHB}>\mathrm{CHB}$ \\
\hline TRBV1 1-3|TRBJ2-4 & 0.00748 & $\mathrm{AHB}>\mathrm{CHB}$ & TRBV21-1|TRBJ1-6 & 0.03520 & $\mathrm{AHB}<\mathrm{CHB}$ \\
\hline TRBV1 1-2|TRBJ1-3 & 0.00774 & $\mathrm{AHB}<\mathrm{CHB}$ & TRBV6-4|TRBJ2-6 & 0.03847 & $\mathrm{AHB}>\mathrm{CHB}$ \\
\hline TRBV18|TRBJ1-4 & 0.00793 & $\mathrm{AHB}<\mathrm{CHB}$ & TRBV7-6|TRBJ1-6 & 0.04088 & $\mathrm{AHB}<\mathrm{CHB}$ \\
\hline TRBV30|TRBJ1-4 & 0.00802 & $\mathrm{AHB}>\mathrm{CHB}$ & TRBV7-6|TRBJ1-2 & 0.04124 & $\mathrm{AHB}<\mathrm{CHB}$ \\
\hline TRBV10-3|TRBJ1-6 & 0.00852 & $\mathrm{AHB}<\mathrm{CHB}$ & TRBV7-8|TRBJ1-6 & 0.04200 & $\mathrm{AHB}<\mathrm{CHB}$ \\
\hline TRBV30|TRBJ1-3 & 0.01086 & $\mathrm{AHB}>\mathrm{CHB}$ & TRBV15|TRBJ1-5 & 0.04326 & $\mathrm{AHB}<\mathrm{CHB}$ \\
\hline TRBV5-8|TRBJ1-3 & 0.01107 & $\mathrm{AHB}>\mathrm{CHB}$ & TRBV2|TRBJ1-1 & 0.04336 & $\mathrm{AHB}<\mathrm{CHB}$ \\
\hline TRBV10-2|TRBJ1-6 & 0.01131 & $\mathrm{AHB}<\mathrm{CHB}$ & TRBV10-3|TRBJ1-5 & 0.04544 & $\mathrm{AHB}<\mathrm{CHB}$ \\
\hline TRBV11-1|TRBJ1-2 & 0.01266 & $\mathrm{AHB}<\mathrm{CHB}$ & TRBV27|TRBJ1-3 & 0.04720 & $\mathrm{AHB}>\mathrm{CHB}$ \\
\hline TRBV7-2|TRBJ2-1 & 0.01369 & $\mathrm{AHB}<\mathrm{CHB}$ & TRBV3-1|TRBJ2-7 & 0.04920 & $\mathrm{AHB}<\mathrm{CHB}$ \\
\hline TRBV4-2|TRBJ1-5 & 0.01422 & $\mathrm{AHB}<\mathrm{CHB}$ & TRBV7-3|TRBJ1-2 & 0.04964 & $\mathrm{AHB}<\mathrm{CHB}$ \\
\hline TRBV10-1|TRBJ1-3 & 0.01847 & $\mathrm{AHB}>\mathrm{CHB}$ & TRBV10-2|TRBJ1-5 & 0.04972 & $\mathrm{AHB}<\mathrm{CHB}$ \\
\hline TRBV12-3|TRBJ2-2 & 0.01877 & $\mathrm{AHB}>\mathrm{CHB}$ & & & \\
\hline
\end{tabular}


Table 4 Comparison of clonal frequency $(\mathrm{V}-\mathrm{J})$ between $\mathrm{AHB}$ and $\mathrm{HC}(\mathrm{P}<0.001)$

\begin{tabular}{|c|c|c|c|c|c|}
\hline VJ & $\mathbf{P}$ & Mean value -comparing & VJ & $\mathbf{P}$ & Mean value -comparing \\
\hline TRBV28|TRBJ1-2 & $4.80 \mathrm{E}-24$ & $\mathrm{AHB}<\mathrm{HC}$ & TRBV1 1-2|TRBJ1-2 & $2.34 \mathrm{E}-05$ & $\mathrm{AHB}<\mathrm{HC}$ \\
\hline TRBV7-2|TRBJ1-6 & $4.02 \mathrm{E}-18$ & $\mathrm{AHB}<\mathrm{HC}$ & TRBV29-1|TRBJ1-5 & 3.30E-05 & $\mathrm{AHB}<\mathrm{HC}$ \\
\hline TRBV5-4|TRBJ2-3 & $3.46 \mathrm{E}-15$ & $\mathrm{AHB}<\mathrm{HC}$ & TRBV12-3|TRBJ1-1 & 3.39E-05 & $\mathrm{AHB}<\mathrm{HC}$ \\
\hline TRBV18|TRBJ2-1 & $2.54 \mathrm{E}-13$ & $\mathrm{AHB}<\mathrm{HC}$ & TRBV18|TRBJ1-1 & $3.78 \mathrm{E}-05$ & $\mathrm{AHB}<\mathrm{HC}$ \\
\hline TRBV6-2|TRBJ2-1 & $2.59 \mathrm{E}-12$ & $\mathrm{AHB}<\mathrm{HC}$ & TRBV4-1|TRBJ2-4 & 7.19E-05 & $\mathrm{AHB}<\mathrm{HC}$ \\
\hline TRBV28|TRBJ2-1 & $7.71 \mathrm{E}-11$ & $\mathrm{AHB}<\mathrm{HC}$ & TRBV15|TRBJ2-1 & $8.21 \mathrm{E}-05$ & $\mathrm{AHB}<\mathrm{HC}$ \\
\hline TRBV7-2|TRBJ2-6 & $1.61 \mathrm{E}-10$ & $\mathrm{AHB}<\mathrm{HC}$ & TRBV2|TRBJ1-1 & $9.10 \mathrm{E}-05$ & $\mathrm{AHB}<\mathrm{HC}$ \\
\hline TRBV18|TRBJ2-2 & $5.65 \mathrm{E}-10$ & $\mathrm{AHB}<\mathrm{HC}$ & TRBV10-3|TRBJ1-1 & $9.46 \mathrm{E}-05$ & $\mathrm{AHB}<\mathrm{HC}$ \\
\hline TRBV1 1-2|TRBJ1-3 & $9.66 \mathrm{E}-10$ & $\mathrm{AHB}<\mathrm{HC}$ & TRBV19|TRBJ1-2 & 0.000113473 & $\mathrm{AHB}<\mathrm{HC}$ \\
\hline TRBV6-2|TRBJ2-4 & 2.93E-09 & $\mathrm{AHB}<\mathrm{HC}$ & TRBV19|TRBJ1-5 & 0.000117244 & $\mathrm{AHB}<\mathrm{HC}$ \\
\hline TRBV18|TRBJ1-5 & $5.11 \mathrm{E}-09$ & $\mathrm{AHB}<\mathrm{HC}$ & TRBV5-4|TRBJ2-6 & 0.000118196 & $\mathrm{AHB}<\mathrm{HC}$ \\
\hline TRBV5-5|TRBJ2-5 & $6.09 \mathrm{E}-09$ & $\mathrm{AHB}<\mathrm{HC}$ & TRBV19|TRBJ1-6 & 0.000142831 & $\mathrm{AHB}<\mathrm{HC}$ \\
\hline TRBV20-1|TRBJ1-2 & $6.43 \mathrm{E}-09$ & $\mathrm{AHB}<\mathrm{HC}$ & TRBV9|TRBJ1-3 & 0.000190044 & $\mathrm{AHB}<\mathrm{HC}$ \\
\hline TRBV28|TRBJ1-3 & $1.56 \mathrm{E}-08$ & $\mathrm{AHB}<\mathrm{HC}$ & TRBV5-5|TRBJ1-5 & 0.000199098 & $\mathrm{AHB}<\mathrm{HC}$ \\
\hline TRBV18|TRBJ1-4 & $2.45 \mathrm{E}-08$ & $\mathrm{AHB}<\mathrm{HC}$ & TRBV3-1|TRBJ2-7 & 0.000218947 & $\mathrm{AHB}<\mathrm{HC}$ \\
\hline TRBV7-2|TRBJ2-3 & 2.69E-08 & $\mathrm{AHB}<\mathrm{HC}$ & TRBV6-1|TRBJ1-3 & 0.000227591 & $\mathrm{AHB}<\mathrm{HC}$ \\
\hline TRBV7-2|TRBJ2-4 & $3.04 \mathrm{E}-08$ & $\mathrm{AHB}<\mathrm{HC}$ & TRBV28|TRBJ1-1 & 0.000285611 & $\mathrm{AHB}<\mathrm{HC}$ \\
\hline TRBV7-2|TRBJ1-1 & $4.53 \mathrm{E}-08$ & $\mathrm{AHB}<\mathrm{HC}$ & TRBV5-4|TRBJ2-2 & 0.000286058 & $\mathrm{AHB}<\mathrm{HC}$ \\
\hline TRBV23-1|TRBJ2-3 & $9.69 \mathrm{E}-08$ & $\mathrm{AHB}<\mathrm{HC}$ & TRBV5-4|TRBJ1-2 & 0.000306129 & $\mathrm{AHB}<\mathrm{HC}$ \\
\hline TRBV5-5|TRBJ2-1 & $1.12 \mathrm{E}-07$ & $\mathrm{AHB}<\mathrm{HC}$ & TRBV12-3|TRBJ1-2 & 0.000315338 & $\mathrm{AHB}<\mathrm{HC}$ \\
\hline TRBV6-2|TRBJ2-7 & $1.47 \mathrm{E}-07$ & $\mathrm{AHB}<\mathrm{HC}$ & TRBV1 1-2|TRBJ2-2 & 0.000315564 & $\mathrm{AHB}<\mathrm{HC}$ \\
\hline TRBV20-1|TRBJ2-3 & $1.83 \mathrm{E}-07$ & $\mathrm{AHB}<\mathrm{HC}$ & TRBV10-3|TRBJ1-6 & 0.000323084 & $\mathrm{AHB}<\mathrm{HC}$ \\
\hline TRBV5-6|TRBJ2-5 & $2.00 \mathrm{E}-07$ & $\mathrm{AHB}<\mathrm{HC}$ & TRBV14|TRBJ2-7 & 0.000435467 & $\mathrm{AHB}<\mathrm{HC}$ \\
\hline TRBV23-1|TRBJ2-5 & $2.59 \mathrm{E}-07$ & $\mathrm{AHB}<\mathrm{HC}$ & TRBV23-1|TRBJ2-1 & 0.000520227 & $\mathrm{AHB}<\mathrm{HC}$ \\
\hline TRBV7-3|TRBJ2-1 & $3.62 \mathrm{E}-07$ & $\mathrm{AHB}<\mathrm{HC}$ & TRBV6-2|TRBJ2-5 & 0.000527129 & $\mathrm{AHB}<\mathrm{HC}$ \\
\hline TRBV12-3|TRBJ2-1 & $4.29 \mathrm{E}-07$ & $\mathrm{AHB}<\mathrm{HC}$ & TRBV6-5|TRBJ1-2 & 0.000540139 & $\mathrm{AHB}<\mathrm{HC}$ \\
\hline TRBV10-3|TRBJ2-5 & $1.14 \mathrm{E}-06$ & $\mathrm{AHB}<\mathrm{HC}$ & TRBV5-4|TRBJ1-6 & 0.000558084 & $\mathrm{AHB}<\mathrm{HC}$ \\
\hline TRBV7-2|TRBJ1-4 & 1.69E-06 & $\mathrm{AHB}<\mathrm{HC}$ & TRBV18|TRBJ2-6 & 0.000563219 & $\mathrm{AHB}<\mathrm{HC}$ \\
\hline TRBV15|TRBJ1-5 & $4.34 \mathrm{E}-06$ & $\mathrm{AHB}<\mathrm{HC}$ & TRBV6-2|TRBJ2-6 & 0.000656795 & $\mathrm{AHB}<\mathrm{HC}$ \\
\hline TRBV1 1-2|TRBJ2-4 & 4.37E-06 & $\mathrm{AHB}<\mathrm{HC}$ & TRBV12-5|TRBJ2-1 & 0.000660101 & $\mathrm{AHB}<\mathrm{HC}$ \\
\hline TRBV11-1|TRBJ2-1 & $5.25 \mathrm{E}-06$ & $\mathrm{AHB}<\mathrm{HC}$ & TRBV2|TRBJ1-3 & 0.000696902 & $\mathrm{AHB}<\mathrm{HC}$ \\
\hline TRBV5-5|TRBJ1-2 & $6.84 \mathrm{E}-06$ & $\mathrm{AHB}<\mathrm{HC}$ & TRBV6-5|TRBJ1-5 & 0.00076708 & $\mathrm{AHB}<\mathrm{HC}$ \\
\hline TRBV6-2|TRBJ2-2 & 1.13E-05 & $\mathrm{AHB}<\mathrm{HC}$ & TRBV19|TRBJ1-4 & 0.000812351 & $\mathrm{AHB}<\mathrm{HC}$ \\
\hline TRBV10-3|TRBJ1-5 & $1.41 \mathrm{E}-05$ & $\mathrm{AHB}<\mathrm{HC}$ & TRBV5-8|TRBJ2-3 & 0.00083316 & $\mathrm{AHB}<\mathrm{HC}$ \\
\hline TRBV6-5|TRBJ2-4 & $1.45 \mathrm{E}-05$ & $\mathrm{AHB}<\mathrm{HC}$ & TRBV3-1|TRBJ1-3 & 0.000874836 & $\mathrm{AHB}<\mathrm{HC}$ \\
\hline TRBV7-2|TRBJ2-1 & 1.65E-05 & $\mathrm{AHB}<\mathrm{HC}$ & TRBV4-2|TRBJ2-4 & 0.000879734 & $\mathrm{AHB}<\mathrm{HC}$ \\
\hline TRBV28|TRBJ2-7 & $1.65 \mathrm{E}-05$ & $\mathrm{AHB}<\mathrm{HC}$ & TRBV5-4|TRBJ2-4 & 0.000890673 & $\mathrm{AHB}<\mathrm{HC}$ \\
\hline
\end{tabular}

respectively; was no significant difference is found (data no shown).

\section{Comparison of clonal overlap rate of TcRBV CDR3 between groups}

The clonal overlap rate between samples in each group was obtained from the profile of immune repertoire (IR) that was derived from HTS and IR alignment. The Baroni-Urbani and Buser (BUB) index was used to indicate the clonal overlap rate between the samples, and there was no significant difference between the three groups $(P>0.05$, Additional file 1: Tab. S2). The heatmap and boxplot of the overlap rate are shown (Additional file 2: Fig. S3). 
Table 5 Comparison of clonal frequency $(\mathrm{V}-\mathrm{J})$ between $\mathrm{CHB}$ and $\mathrm{HC}(\mathrm{P}<0.001)$

\begin{tabular}{|c|c|c|c|c|c|}
\hline VJ & $\mathbf{P}$ & Mean value -comparing & VJ & $P$ & Mean value -comparing \\
\hline TRBV28|TRBJ1-3 & 4.67E-17 & $\mathrm{CHB}<\mathrm{HC}$ & TRBV30|TRBJ2-3 & $2.85 \mathrm{E}-05$ & $\mathrm{CHB}<\mathrm{HC}$ \\
\hline TRBV5-4|TRBJ2-7 & $5.96 \mathrm{E}-17$ & $\mathrm{CHB}<\mathrm{HC}$ & TRBV11-1|TRBJ2-1 & 4.26E-05 & $\mathrm{CHB}<\mathrm{HC}$ \\
\hline TRBV4-3|TRBJ2-3 & $6.27 \mathrm{E}-14$ & $\mathrm{CHB}<\mathrm{HC}$ & TRBV27|TRBJ1-3 & $6.34 \mathrm{E}-05$ & $\mathrm{CHB}<\mathrm{HC}$ \\
\hline TRBV5-4|TRBJ2-3 & 9.65E-14 & $\mathrm{CHB}<\mathrm{HC}$ & TRBV11-2|TRBJ2-3 & $6.67 \mathrm{E}-05$ & $\mathrm{CHB}<\mathrm{HC}$ \\
\hline TRBV18|TRBJ2-3 & $1.01 \mathrm{E}-12$ & $\mathrm{CHB}<\mathrm{HC}$ & TRBV6-2|TRBJ2-3 & $6.72 \mathrm{E}-05$ & $\mathrm{CHB}<\mathrm{HC}$ \\
\hline TRBV6-2|TRBJ2-1 & $1.58 \mathrm{E}-12$ & $\mathrm{CHB}<\mathrm{HC}$ & TRBV4-3|TRBJ1-6 & $8.35 \mathrm{E}-05$ & $\mathrm{CHB}<\mathrm{HC}$ \\
\hline TRBV28|TRBJ1-4 & $2.13 \mathrm{E}-12$ & $\mathrm{CHB}<\mathrm{HC}$ & TRBV29-1|TRBJ2-3 & $8.71 \mathrm{E}-05$ & $\mathrm{CHB}<\mathrm{HC}$ \\
\hline TRBV19|TRBJ2-4 & 2.05E-10 & $\mathrm{CHB}<\mathrm{HC}$ & TRBV29-1|TRBJ2-7 & 0.000146 & $\mathrm{CHB}<\mathrm{HC}$ \\
\hline TRBV28|TRBJ2-2 & $2.78 \mathrm{E}-10$ & $\mathrm{CHB}<\mathrm{HC}$ & TRBV6-2|TRBJ2-2 & 0.000150 & $\mathrm{CHB}<\mathrm{HC}$ \\
\hline TRBV19|TRBJ2-7 & $7.28 \mathrm{E}-10$ & $\mathrm{CHB}<\mathrm{HC}$ & TRBV28|TRBJ1-6 & 0.000159 & $\mathrm{CHB}<\mathrm{HC}$ \\
\hline TRBV30|TRBJ1-5 & 4.23E-09 & $\mathrm{CHB}<\mathrm{HC}$ & TRBV7-3|TRBJ2-7 & 0.000164 & $\mathrm{CHB}<\mathrm{HC}$ \\
\hline TRBV19|TRBJ1-2 & 2.03E-08 & $\mathrm{CHB}<\mathrm{HC}$ & TRBV24-1|TRBJ2-7 & 0.000171 & $\mathrm{CHB}<\mathrm{HC}$ \\
\hline TRBV19|TRBJ2-3 & $2.46 \mathrm{E}-08$ & $\mathrm{CHB}<\mathrm{HC}$ & TRBV23-1|TRBJ2-3 & 0.000181 & $\mathrm{CHB}<\mathrm{HC}$ \\
\hline TRBV18|TRBJ2-1 & 2.79E-08 & $\mathrm{CHB}<\mathrm{HC}$ & TRBV20-1|TRBJ2-2 & 0.000217 & $\mathrm{CHB}<\mathrm{HC}$ \\
\hline TRBV28|TRBJ2-1 & $8.28 \mathrm{E}-08$ & $\mathrm{CHB}<\mathrm{HC}$ & TRBV7-2|TRBJ2-6 & 0.000308 & $\mathrm{CHB}<\mathrm{HC}$ \\
\hline TRBV4-3|TRBJ2-1 & 1.05E-07 & $\mathrm{CHB}<\mathrm{HC}$ & TRBV7-3|TRBJ2-5 & 0.000338 & $\mathrm{CHB}<\mathrm{HC}$ \\
\hline TRBV4-3|TRBJ1-5 & $3.68 \mathrm{E}-07$ & $\mathrm{CHB}<\mathrm{HC}$ & TRBV14|TRBJ2-1 & 0.000503 & $\mathrm{CHB}<\mathrm{HC}$ \\
\hline TRBV4-3|TRBJ2-2 & 1.10E-06 & $\mathrm{CHB}<\mathrm{HC}$ & TRBV7-2|TRBJ1-3 & 0.000532 & $\mathrm{CHB}<\mathrm{HC}$ \\
\hline TRBV12-5|TRBJ2-1 & $1.31 \mathrm{E}-06$ & $\mathrm{CHB}<\mathrm{HC}$ & TRBV7-2|TRBJ1-5 & 0.000657 & $\mathrm{CHB}<\mathrm{HC}$ \\
\hline TRBV10-3|TRBJ2-7 & 2.17E-06 & $\mathrm{CHB}<\mathrm{HC}$ & TRBV21-1|TRBJ2-1 & 0.000718 & $\mathrm{CHB}<\mathrm{HC}$ \\
\hline TRBV7-3|TRBJ2-1 & $5.80 \mathrm{E}-06$ & $\mathrm{CHB}<\mathrm{HC}$ & TRBV7-2|TRBJ2-3 & 0.000784 & $\mathrm{CHB}<\mathrm{HC}$ \\
\hline TRBV20-1|TRBJ2-5 & $9.01 \mathrm{E}-06$ & $\mathrm{CHB}<\mathrm{HC}$ & TRBV21-1|TRBJ2-7 & 0.000882 & $\mathrm{CHB}<\mathrm{HC}$ \\
\hline TRBV6-2|TRBJ2-7 & $1.28 \mathrm{E}-05$ & $\mathrm{CHB}<\mathrm{HC}$ & & & \\
\hline
\end{tabular}

Relationship between CDR3 diversity and immune system stability

The diversity of $\mathrm{V} / \mathrm{D} / \mathrm{J}$ gene clones in the three groups were compared and analyzed based on the abovementioned $\mathrm{T}$ cell CDR3 immune repertoire (IR). SE and IS of the three groups were compared considering each clone as different species, and the number of each clone sequence as the richness of the species. There was no significant difference in the SE and IS found between the three groups $(\mathrm{P}>0.05)$. The detailed $\mathrm{SE}$ and IS are shown in Fig. 3.

\section{Discussion}

$\mathrm{T}$ cells play an important role in limiting HBV infection, and their CDR3 of the TCR $\beta$ chain is synthesized by three genes of the $\mathrm{V} / \mathrm{D} / \mathrm{J}$ segments, through rearrangement of the gene segments [23]. This forms a variety of CDR3 clones that can respond to various antigens. The diversity of CDR3 can regulate immune homeostasis by affecting the cytotoxic activity of effector T cells [24, 25]. HBsAg SC is a sign of good outcome in subjects with asymptomatic or acute HBV infection although the mechanism involved is still unclear [26]. This study analyzed the clone type and diversity of CDR3 immune repertoire (IR) in resolved acute hepatitis $B$ (AHB) subjects with $\mathrm{HBsAb}$ positive $(\mathrm{HBs} A b+)$, and screened the clone types that would be relate to HBsAg SC in subjects infected with HBV.

Immune repertoire (IR) refers to the sum of all functional diversity $\mathrm{B}$ cells and $\mathrm{T}$ cells in the circulatory system of an individual at any given time. High throughput sequencing (HTS) technology can truly and comprehensively discover the genetic information of all T-cell receptors (TcR), and studying the CDR3 sequence of all TcRs [27]. HTS could broadly reveal the diversity and complexity of TcR; it is thus an important technology for exploring IR. The adaptive immune system monitors pathogens through the diversity of CDR3 in IR [28].

To study the difference of CDR3 IR among subjects with or without $\mathrm{HBs} A \mathrm{~b}$ positive $(\mathrm{HBs} \mathrm{Ab}+), 5 \mathrm{AHB}$ cases $(\mathrm{HBs} \mathrm{Ab}+)$ were compared with $5 \mathrm{CHB}$ cases and 3 healthy controls $(\mathrm{HC})$. The results showed that the clone overlap rate of the $\mathrm{AHB}$ group was the highest and that the $\mathrm{HC}$ group was the second among the three groups. This higher overlapping rate represents a higher CDR3 homology, which means that the subject with a higher overlapping rate of CDR3 undergoes easier recovery after HBV infection. 


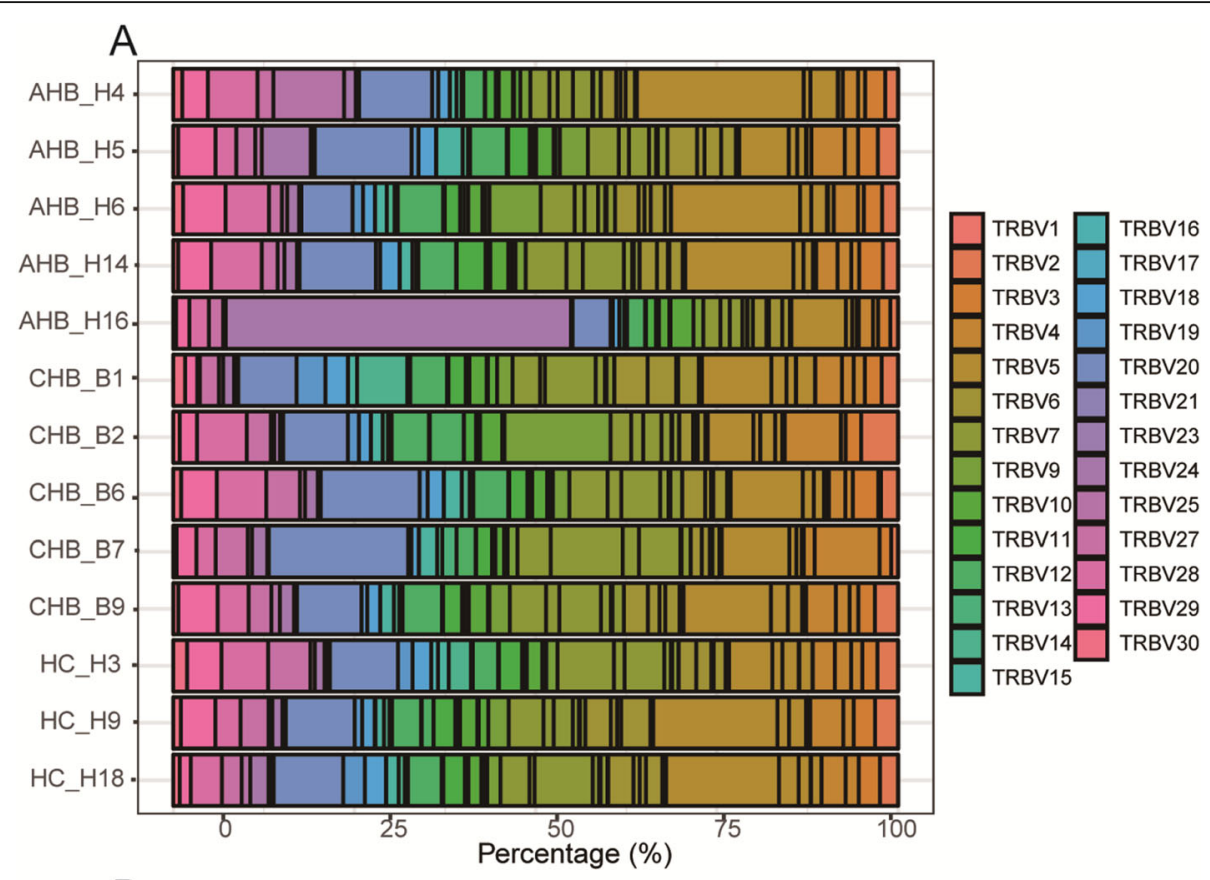

B

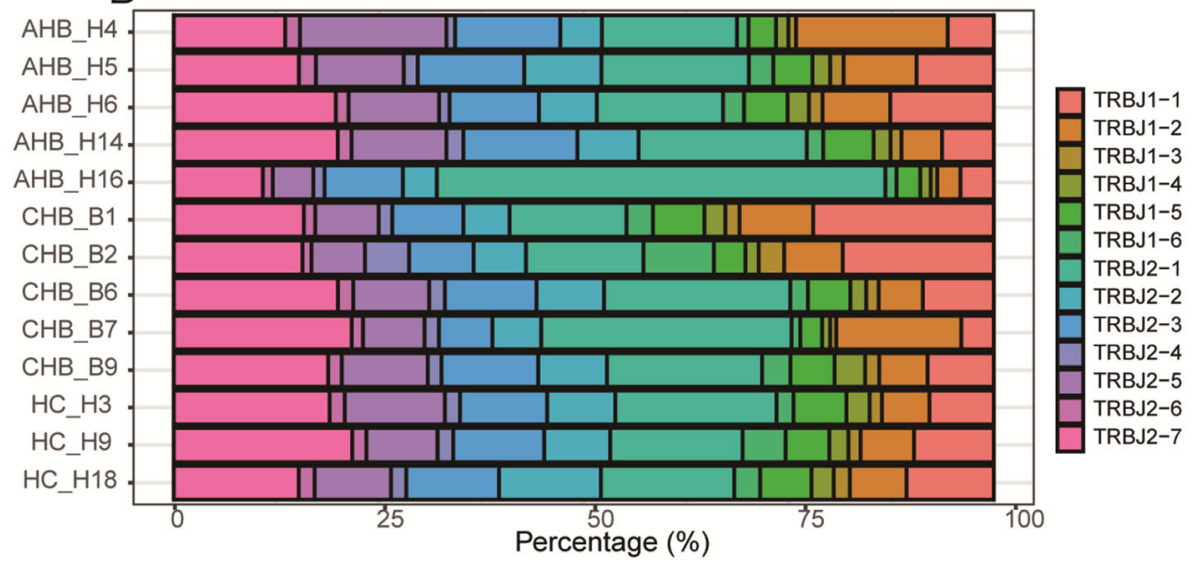

Fig. 2 Semi-quantitative results of BV or BJ segment usage in each subject of the three groups (AHB, CHB, and HC). a BV segment usage in PBMC from each subject; $\mathbf{b}$ BJ segment usage in PBMC from each subject
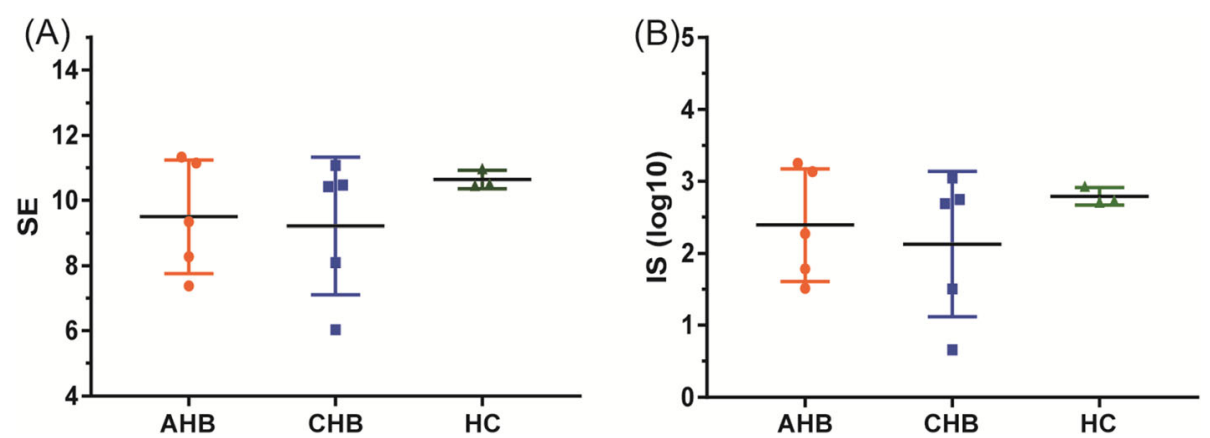

Fig. 3 SE and IE of CDR3 diversity. Shannon entropy (SE) index (a) and inverse Simpson's (IE) index (b) used as indicators of CDR3 diversity of TRBV in groups 
In order to further explore the effect of different TcRBV clone types on the HBsAg SC in subjects with HBV infection, we compared the top ten clone types between three groups and obtained the clone types (TcRBV20-1/BD1/BJ1-2) with significant differences between $\mathrm{AHB}$ and $\mathrm{HC}$ groups. This indicates that the clone types may be related to different outcomes in subjects with HBV infection (AHB or CHB) [29]. Among non-dominant clones, there were $57 \mathrm{TcRBV}$ clone types with a significant difference in AHB compared with that of the CHB group, of which TcRBV6-4/BD1 (BD2) /BJ2-2 had the highest cloning frequency, and a higher frequency was found in the $\mathrm{AHB}$ group than in $\mathrm{CHB}$ group; the frequency was also higher in the $\mathrm{AHB}$ group than that in the $\mathrm{HC}$ group, indicating the close association of this genotype with HBsAg SC [30]; however, the number of cases needs be expanded for further verification. Furthermore, whether the different TcRBV genotypes are specific for HBV antigen, should be confirmed in future studies.

Diversity is an indicator to measure the variation among hosts. In the immune system, the higher diversity of immune cells, the higher is their stability and the stronger is their ability to resist the invasion of various antigens (pathogens). Conversely, the host is more susceptible to pathogens and tumors, if the diversity of the immune system is low (that is, smaller number of diverse $\mathrm{T}$ cell clones) [31-33]. After HBV infection, some of the infected subjects manifest acute asymptomatic infection and HBsAg SC in peripheral blood, becoming convalescent. Some subjects progress to chronic persistent HBV infection develop chronic hepatitis B (CHB). In addition, the different outcomes of HBV infection may be attributed to the diversity of individual immune status, especially the diversity of $\mathrm{T}$ cell clones $[5,25]$.

HBsAb production is the aim of hepatitis $B$ vaccination. However, $5-10 \%$ of recipients is unable to produce a protective level of antibodies against HBsAg after a standard vaccine course [34]. There are few reports about the relationship of the profile of the TcRBV family and the result of HBV vaccination. Whitacre, D. C. et al. have indicated that the clonal change of TcRBV gene in $\mathrm{CD} 4+\mathrm{T}$ cells is one of the important factors affecting the immune response of the recipients to hepatitis $\mathrm{B}$ vaccine [35].

In this study, diversity indices (SE and IS) were used to assess the diversity of $\mathrm{T}$ cell clones (TcRBV CDR3), and the results showed no significant difference between the three groups in the CDR3 sequence, suggesting that there was no significant difference in immune status among the three groups. Miyasaka et al. suggested that an increased TCR $\beta$ chain diversity and a decreased B cell receptor (BCR) IgG $\mathrm{H}$ chain diversity after the second $\mathrm{HB}$ vaccination could predict a better response to
HB vaccination [6, 36], indicating different mechanisms by which the host produces HBsAb after responding to symptomatic HBV infection or HBV vaccination. The results further hint that the no-response of hepatitis $B$ vaccination can be related to the immune status of the body itself [37], though, further studies with additional cases are needed to confirm this possibility. Additionally, several limitations are present in the present study. First, the number of samples tested in each group was small, especially only three subjects in the HC group. We were also unable to compare sex differences among subjects because only male subjects were used in the AHB group [38].

\section{Conclusions}

The results suggest that there are 57 TcRBV clonotypes may be related to the HBsAg SC in AHB subjects, especially the TcRBV6-4/BD1 (BD2) /BJ2-2. Additionally, there may be no significant relationship between the clonal diversity of TCR $\beta$ chain CDR3 and HBsAg SC. However, further studies with additional subjects are needed to confirm this hypothesis, which will improve the prediction of prognosis of subjects with $\mathrm{HBeAg}+$ CHB.

\section{Supplementary Information}

The online version contains supplementary material available at https://doi. org/10.1186/s12879-021-05816-2.

Additional file 1: Table S1. The information of amplification. Table S2. Clonal overlap rate (BUB index) among the three groups.

Additional file 2: Figure S1. Frequency of $V / J$ gene combinations have significant differences among the three groups $(P<0.001)$. Figure $\mathbf{S 2}$. Frequency of $V / J$ gene combinations have significant differences among the three groups $(0.001<P<0.05)$. Figure S3. Heatmap of clonal overlap rate of CDR3 for samples in each group.

Abbreviations

AHB: Resolved acute hepatitis B; CDR3: Complementarity determining region 3; HTS: High throughput sequencing; IS: Inverse Simpson's index;

PBMC: Peripheral blood mononuclear cells; PCR: Polymerase chain reaction; RT: Reverse-transcription; SC: Seroconversion; SD: Standard deviation;

SE: Shannon entropy index; TCRBV: T-cell receptor beta chain variable region

\section{Acknowledgments}

We sincerely thank all of the subjects participating in the study.

\section{Authors' contributions}

YJZ contributed to the study design, experiments, and the writing the initial draft. XDS collected the clinical data, and helped to perform some

experiments. WJ assisted in experimental design and help to data collection. CZT, JXY, and XYR participated in the study design and experiments. YD and YJZ contributed to the study coordination, technical issues and revision of the manuscript. All authors read and approved the final manuscript.

\section{Funding}

The research was supported by Zhejiang Provincial Natural Science Foundation of China (Grant No. LY19H190004), and the National Science and Technology Major Project (2018ZX10101-001). The funders had no role in the design of the study and collection, analysis, and interpretation of data and in writing the manuscript. 


\section{Availability of data and materials}

The datasets used in the current study are available from the corresponding author on reasonable requirements.

\section{Ethics approval and consent to participate}

Samples were collected after obtaining informed consent from subjects at the First Affiliated Hospital, School of Medicine, Zhejiang University. The samples were collected from patients with written informed consent. The experiment was approved by the ethics committee of the First Affiliated Hospital of Zhejiang University and the methods were carried out in according to relevant guidelines and regulations.

\section{Consent for publication}

Not Applicable.

\section{Competing interests}

The authors declare that they have no competing interests.

\section{Author details}

'Zhejiang Provincial Key Laboratory for Diagnosis and Treatment of Aging and Physic-chemical Injury Diseases, Department of Geriatrics, the First Affiliated Hospital, Zhejiang University School of Medicine, Zhejiang 310003, Hangzhou, China. ${ }^{2}$ State Key Laboratory for Diagnosis and Treatment of Infectious Diseases, National Clinical Research Center for Infectious Diseases, Collaborative Innovation Center for Diagnosis and Treatment of Infectious Diseases, the First Affiliated Hospital, Zhejiang University School of Medicine, Zhejiang 310003, Hangzhou, China. ${ }^{3}$ Department of Hepatobiliary and Pancreatic Surgery, the First Affiliated Hospital, Zhejiang University School of Medicine, Zhejiang 310003, Hangzhou, China.

\section{Received: 16 August 2020 Accepted: 17 January 2021}

Published online: 23 January 2021

\section{References}

1. Tang LSY, Covert E, Wilson E, Kottilil S. Chronic hepatitis B infection: a review. JAMA. 2018;319(17):1802-13.

2. Terrault NA, Lok ASF, McMahon BJ, Chang KM, Hwang JP, Jonas MM, Brown RS Jr, Bzowej NH, Wong JB. Update on prevention, diagnosis, and treatment of chronic hepatitis B: AASLD 2018 hepatitis B guidance. Hepatology. 2018; 67(4):1560-99.

3. Jin Y, Geng N, Zhao L, Li Y, Zheng L, Zhu W, Sheng Q, An Z, Wang J, Dou X, et al. The prevalence of HBV infection: a retrospective study of 13-years in a public Hospital of Northeast China. Viral Immunol. 2020;33(2):99-104.

4. Lu J, Wu J, Xie F, Tian J, Tang X, Guo H, Ma J, Xu P, Mao L, Xu H, et al. CD4(+) T cell-released extracellular vesicles potentiate the efficacy of the HBsAg vaccine by enhancing B cell responses. Adv Sci (Weinh). 2019;6(23): 1802219.

5. Jiang Q, Zhao T, Zheng W, Zhou J, Wang H, Dong H, Chen Y, Tang X, Liu C, Ye L, et al. Patient-shared TCRB-CDR3 clonotypes correlate with favorable prognosis in chronic hepatitis B. Eur J Immunol. 2018;48(9):1539-49.

6. Miyasaka A, Yoshida Y, Wang T, Takikawa Y. Next-generation sequencing analysis of the human T-cell and B-cell receptor repertoire diversity before and after hepatitis B vaccination. Hum Vaccin Immunother. 2019;15(11): 2738-53.

7. Wang J, Cao D, Yang J. Exosomes in hepatitis B virus transmission and related immune response. Tohoku J Exp Med. 2020;252(4):309-20.

8. Dash P, Fiore-Gartland AJ, Hertz T, Wang GC, Sharma S, Souquette A, Crawford JC, Clemens EB, Nguyen THO, Kedzierska K, et al. Quantifiable predictive features define epitope-specific T cell receptor repertoires. Nature. 2017;547(7661):89-93.

9. Zheng M, Zhang X, Zhou Y, Tang J, Han Q, Zhang Y, Ni Q, Chen G, Jia Q, Yu $H$, et al. TCR repertoire and CDR3 motif analyses depict the role of $\mathrm{a} \beta \mathrm{T}$ cells in Ankylosing spondylitis. EBioMedicine. 2019;47:414-26.

10. Yang J, Chen J, He J, Xie Y, Zhu Y, Cao H, Li L. Profiling the repertoire of Tcell receptor beta-chain variable genes in peripheral blood lymphocytes from subjects who have recovered from acute hepatitis B virus infection. Cell Mol Immunol. 2014;11(4):332-42.

11. Elhanati Y, Sethna Z, Callan CG Jr, Mora T, Walczak AM. Predicting the spectrum of TCR repertoire sharing with a data-driven model of recombination. Immunol Rev. 2018;284(1):167-79.
12. Sarin SK, Kumar M, Lau GK, Abbas Z, Chan HLY, Chen CJ, Chen DS, Chen HL, Chen PJ, Chien RN, et al. Asian-Pacific clinical practice guidelines on the management of hepatitis B: a 2015 update. Hepatol Int. 2016;10(1):1-98.

13. Akram A, Islam SMR, Munshi SU, Tabassum S. Detection of hepatitis B virus DNA among chronic and potential occult HBV patients in resource-limited settings by loop-mediated isothermal amplification assay. J Viral Hepatitis. 2018;25(11):1306-11.

14. Yang J, Sheng G, Xiao D, Shi H, Wu W, Lu H, Cao H, Li L. The frequency and skewed T-cell receptor beta-chain variable patterns of peripheral CD4(+ )CD25(+) regulatory T-cells are associated with hepatitis B e antigen seroconversion of chronic hepatitis B patients during antiviral treatment. Cell Mol Immunol. 2016;13(5):678-87.

15. Hou X, Guo Q, Wei W, Guo L, Guo D, Zhang L. Screening of Genes Related to Early and Late Flowering in Tree Peony Based on Bulked Segregant RNA Sequencing and Verification by Quantitative Real-Time PCR. Molecules. 2018;23(3):289.

16. Wang X, Hu Y, Liu X, Yu J, Xu P, Wei G, Jin C, Wu W, Fu H, Ding L, et al. Quantitative characterization of T-cell repertoire alteration in Chinese patients with B-cell acute lymphocyte leukemia after CAR-T therapy. Bone Marrow Transplant. 2019;54(12):2072-80.

17. Gao X, Xu C, Li B, Zhao L, Yu Y, Su Y, Wang J, Liu N, Chen J, Hu J, et al. Quantitative analysis of thymus-independent donor-derived T cell expansion in transplant patients. Biol Blood Marrow Transplant. 2020;26(2): 242-53.

18. Chen Y, Xu Y, Zhao M, Liu Y, Gong M, Xie C, Wu H, Wang Z. Highthroughput $T$ cell receptor sequencing reveals distinct repertoires between tumor and adjacent non-tumor tissues in HBV-associated HCC. Oncoimmunology. 2016;5(10):e1219010.

19. Birtel J, Walser J-C, Pichon S, Bürgmann H, Matthews B. Estimating bacterial diversity for ecological studies: methods, metrics, and assumptions. PLoS One. 2015;10(4):e0125356.

20. Linninge C, Roth B, Erlanson-Albertsson C, Molin G, Toth E, Ohlsson B. Abundance of Enterobacteriaceae in the colon mucosa in diverticular disease. World J Gastrointest Pathophysiol. 2018;9(1):18-27.

21. Zhang L, Cham J, Paciorek A, Trager J, Sheikh N, Fong L. 3D: diversity, dynamics, differential testing - a proposed pipeline for analysis of nextgeneration sequencing T cell repertoire data. BMC Bioinformatics. 2017; 18(1):129.

22. Yousfi Monod M, Giudicelli V, Chaume D, Lefranc M-P. IMGT/ JunctionAnalysis: the first tool for the analysis of the immunoglobulin and T cell receptor complex V-J and V-D-J JUNCTIONs. Bioinformatics (Oxford, England). 2004;20 Suppl 1:1379-85.

23. Lu J, Van Laethem F, Bhattacharya A, Craveiro M, Saba I, Chu J, Love NC Tikhonova A, Radaev S, Sun X, et al. Molecular constraints on CDR3 for thymic selection of MHC-restricted TCRs from a random pre-selection repertoire. Nat Commun. 2019;10(1):1019.

24. Nielsen SCA, Boyd SD. Human adaptive immune receptor repertoire analysis-past, present, and future. Immunol Rev. 2018;284(1):9-23.

25. Wisskirchen K, Kah J, Malo A, Asen T, Volz T, Allweiss L, Wettengel JM, Lütgehetmann M, Urban S, Bauer T, et al. T cell receptor grafting allows virological control of hepatitis B virus infection. J Clin Invest. 2019;129(7):2932-45.

26. Fan $H$, Lin L, Jia S, Xie M, Luo C, Tan X, Ying R, Guan Y, Li F. Interferon alpha treatment leads to a high rate of hepatitis $B$ surface antigen seroconversion in Chinese children with chronic hepatitis B. J Viral Hepatitis. 2019;26(Suppl 1):77-84.

27. Singh M, Al-Eryani G, Carswell S, Ferguson JM, Blackburn J, Barton K, Roden D, Luciani F, Giang Phan T, Junankar S, et al. High-throughput targeted long-read single cell sequencing reveals the clonal and transcriptional landscape of lymphocytes. Nat Commun. 2019;10(1):3120.

28. Wong GK, Heather JM, Barmettler S, Cobbold M. Immune dysregulation in immunodeficiency disorders: the role of T-cell receptor sequencing. J Autoimmun. 2017;80:1-9.

29. Jiang $Q$, Zhao T, Zheng W, Zhou J, Wang H, Dong H, Chen Y, Tang X, Liu C, Ye L, et al. Patient-shared TCRbeta-CDR3 clonotypes correlate with favorable prognosis in chronic hepatitis B. Eur J Immunol. 2018;48(9):1539-49.

30. Lim SG, Agcaoili J, De Souza NNA, Chan E. Therapeutic vaccination for chronic hepatitis B: a systematic review and meta-analysis. J Viral Hepatitis. 2019;26(7):803-17.

31. Koh S, Tan AT, Li L, Bertoletti A. Targeted Therapy of Hepatitis B VirusRelated Hepatocellular Carcinoma: Present and Future. Diseases (Basel, Switzerland). 2016;4(1):10. 
32. Gaud G, Lesourne R, Love PE. Regulatory mechanisms in T cell receptor signalling. Nat Rev Immunol. 2018;18(8):485-97.

33. Rivino L, Le Bert N, Gill US, Kunasegaran K, Cheng Y, Tan DZ, Becht E, Hansi NK, Foster GR, Su T-H, et al. Hepatitis B virus-specific T cells associate with viral control upon nucleos(t)ide-analogue therapy discontinuation. J Clin Invest. 2018;128(2):668-81.

34. Yoshioka N, Deguchi M, Hagiya H, Kagita M, Tsukamoto H, Takao M, Yoshida H, Yamamoto N, Akeda Y, Nabetani Y, et al. Durability of immunity by hepatitis $B$ vaccine in Japanese health care workers depends on primary response titers and durations. PLoS One. 2017;12(11):e0187661.

35. Whitacre DC, Peters CJ, Sureau C, Nio K, Li F, Su L, Jones JE, Isogawa M, Sallberg $M$, Frelin $L$, et al. Designing a therapeutic hepatitis $B$ vaccine to circumvent immune tolerance. Hum Vaccin Immunother. 2020;16(2):251-68.

36. Ruggiero E, Nicolay JP, Fronza R, Arens A, Paruzynski A, Nowrouzi A, Urenden G, Lulay C, Schneider S, Goerdt S, et al. High-resolution analysis of the human T-cell receptor repertoire. Nat Commun. 2015;6:8081.

37. Salimzadeh L, Le Bert N, Dutertre C-A, Gill US, Newell EW, Frey C, Hung M, Novikov N, Fletcher S, Kennedy PT, et al. PD-1 blockade partially recovers dysfunctional virus-specific B cells in chronic hepatitis B infection. J Clin Invest. 2018;128(10):4573-87.

38. Lian J, Liu J, Yue Y, Li F, Chen X, Zhang Z, Ping Y, Qin G, Li L, Zhang K, et al. The repertoire features of $T$ cell receptor $\beta$-chain of different age and gender groups in healthy Chinese individuals. Immunol Lett. 2019;208:4451.

\section{Publisher's Note}

Springer Nature remains neutral with regard to jurisdictional claims in published maps and institutional affiliations.

Ready to submit your research? Choose BMC and benefit from:

- fast, convenient online submission

- thorough peer review by experienced researchers in your field

- rapid publication on acceptance

- support for research data, including large and complex data types

- gold Open Access which fosters wider collaboration and increased citations

- maximum visibility for your research: over $100 \mathrm{M}$ website views per year

At $\mathrm{BMC}$, research is always in progress.

Learn more biomedcentral.com/submissions 